\title{
Health e-learning using virtual-reality technology in Algerian universities
}

Type of article: Conference abstract

\author{
Nadji Ahmed Zakariya1, Boudour Rachid1 \\ 1. Embedded Systems Laboratory - ESLA, University of Badji Mokhtar Annaba, \\ Algeria \\ Nadji.zakaria@gmail.com
}

\begin{abstract}
:
Background: The virtual reality environments around the world are increasingly used in many areas, including education, where they offer new learning opportunities. This technology (virtual reality) is used as an information resource or as an educational tool where the student takes an active part in learning by interacting with the device. For the past ten years or so, virtual environments have been used in teaching, especially in history and science.

Methods: Our work focuses on the educational potential offered by this technology at the Algerian University, and for this we have experimented virtual reality applications intended for the education of medicine using a virtual reality helmet "VR BOX", which is a viewer hosting a smartphone. The students and teachers were looking through the VR BOX at a virtual human body and exploring the different body organs in 3D.
\end{abstract}

Results: This simulation, not otherwise possible in class with the classical teaching tools, offered students and teachers the opportunity to immerse themselves in an extremely realistic environment and allowed them to have a fun, memorable and fascinating experience. According to them, the use of this technology could intervene, in addition to the course, to facilitate the understanding of concepts difficult to explain. One of the main advantages of using this technology, say some teachers, is above all the interest and the motivation it arouses among the students. Conclusion: The study presented in this article demonstrates the results of using virtual-reality environments for e-learning in the Algerian University in general, and for Health e-learning in particular. Furthermore, this experience and in view of the availability of virtual reality tools in Algeria at a very reasonable price, shows that virtual reality is very promising for the class of tomorrow and seems reinvigorating the teaching in Algeria as well as elsewhere.

Keywords: e-learning, health, virtual-reality, Medical-education.

\section{Declaration of conflicts}

This article is selected from the abstract's book of the International Conference on Health Sciences and Medical Technologies,10-12 October 2017, Tlemcen, Algeria, ICHSMT' 17.

\section{Authors' biography}

No biography 
Medical Technologies Journal, Volume: 1, Issue: 3, July -September 2017, Pages: 50-51. DOI: https://doi.org/10.26415/2572-004X-vol1iss3p50-51

\section{References}

No references 